\title{
A novel, Value-Focused-Thinking Based, Approach for Modelling Agro-Industrial Decisions Under Scarce Information
}

\author{
Mario Luis Chew-Hernández, ${ }^{1, a}$, Leopoldo Viveros-Rosas ${ }^{2, b}$, Verónica Velázquez-Romero ${ }^{3, b}$ \\ 1,2,3 Technological of Superior Studies of Coacalco, Cabecera Municipal No. 54, Coacalco de Berriozabal, México \\ amario@tesco.edu.mx, blviverosrahotmail.com, cing ind amb@hotmail.com
}

\begin{abstract}
Agro-industrial decision-making is hampered by several, variously-natured, uncertainties. As uncertainty reduction is expensive, the decision modelling process for these industries must strive to use all available information. However, said inclusive effort should be accompanied by an effort to keep modelling assumptions transparent. This work shows the development, from a Value-Focused Thinking perspective, of a model to assess alternatives for improving the operation of a cattle fodder producer. Modelling starts by analyzing and structuring the owner's objectives and proceeds by systematically characterizing, via value judgments or probability distributions, the connections between structured objectives. Constructing the model over a blueprint of connected objectives allows a faithful representation of the understanding of the system behavior while the methodical, one-connection-at-a-time, modelling procedure renders the assumptions used to operationalize each connection visible, facilitating their replacement if more information becomes available. The modelling approach put forward here can support industrial decision making with limited information.
\end{abstract}

Keywords: Decision Analysis, Industrial Management, Value Focused Thinking.

\section{Introduction}

The decision making in businesses and manufactures is hindered by several uncertainties. While large companies may be able to reduce their uncertainty about some elements (for example, by running in-house laboratories) this is not the case of small and medium-sized plants. Thus, managers of these base their decisions on rough-and-ready cost-benefit analyses that include only factors that are known either precisely or quantitatively, disregarding uncertain and qualitative ones. Said approach wastes available information which, duly codified, can be useful for making a decision.

Decision Analysis (DA), pioneered by Howard (1966), aims to help complex decision making, while one DA paradigm, Keeney's Value-Focused Thinking (VFT) (1992), states that a sound decision modeling stems from the decision maker's objectives. This work shows the analysis and modelling, carried out with a VFT worldview, of the operational issues of a small cattle food processing plant. As commanded by the VFT, the analysis begins by identifying and structuring the owner's objectives. The model is then constructed using said structures as a blueprint, allowing a faithful representation of the owner's knowledge of the system behavior. Subjective probability distributions are used to capture owners' and operators' knowledge and scales are constructed for qualitative factors, gaining insight into their importance and meaning.

Regarding related research, several multicriteria decision models (MCDM) applications for agro-industrial problems are available. Zerger et al. (2011), Topping et al. (2019) and Mwambo et al. (2020) used MCDM models and simulation to link regional conservation policies to farm administration; Nikoloski et al. (2017) applied MCMD and DEXI software to assess the feasibility of steering a livestock breeding farm into crop growing; Kocjančič et al. (2018) used goal programming for sustainable farm management; Punantapong (2016) combined DEXI with the Analytic Hierarchical Process to evaluate farm investment alternatives; Yin et al. (2018) applied MCDM for selecting shore areas for mussel aquaculture and Rocchi et al. (2019) to select poultry breeding schemes; Hosseinzade et al. (2017) applied TOPSIS in choosing irrigation flow controllers and Ahmed et al. (2001) used MCDM to include people's nutritional improvements into the feasibility assessment of innovations in self-consumption farms. In addition, Barton et al. (2016) used Bayesian Networks for selecting tree species considering costs and ecological impacts and Prato and Herath (2007) applied MCDM to manage the harvest of rainwater for crop irrigation. The coupling of MCDM and geographic information systems is shown by Agrell et al. (2004) for agro-ecologically managing a Kenyan community, Romano et al. (2015) for identifying suitable farm restoration areas and Jha et al. (2014) and Toosi et al. (2020) for rainwater harvesting planning.

DA has been used for setting swine vaccination and disease prevention policies (Parsons et al., 1986; Silva et al. 2018) and choosing methods for cattle pregnancy detection (Oltenacu et al., 1990) and tuberculosis prevention (Dorshorst et al., 2006). Mathematical programming has been used for biodiesel crops management (Shastri et al., 2011), fertilizer application planning (Monjardino et al., 2015), planting and harvesting scheduling under the risk of frosts (Põldaru and Roots, 2014) or product breakdown (Widodo et al., 2006), holistic farm planning (Lien, 2003) and pig farm operation design (Plà et al., 2004).

No found report takes a VFT approach to agro-industrial decision modelling, with those showing MCDM's assuming that the objectives are somehow clear beforehand, using owners' input only for deriving weights. A VFT approach requires identifying objectives, separating essential from means and rendering the objective structures, steps missing in those researches. The VFT worldview is pushed here even further, by using the objectives structures as a modelling blueprint. Finally, previous works overlook the fact that small agro industries have limited data to base their decisions on. This 
compels the analyst to make the most of the available information, but also to keep modelling assumptions clearly visible when recommendations are drawn. The approach shown here manages to fulfill these requisites.

The following sections detail the treated fodder plant and the development of a model analyzing its problematic. While the described modelling process corresponds to work carried out for a real plant, some parameter values are illustrative.

\section{Plant description}

The fodder consists of corn plant leaves (discarded after the cobs harvest) and nutrients (Figure 1). The plant processes a daily leaf amount of $W_{0}(\mathrm{~kg}$, dry base) with an humidity of $X_{0, H 2 O}$ (g water $/ \mathrm{kg}$ dry leaf). Starting the day, the Stabilized Molasses Tank is filled with $Q_{S}$ liters of sodium sulfate solution of concentration $C_{S}\left(\mathrm{~g} \mathrm{Na}_{2} \mathrm{SO}_{4} / \mathrm{l}\right)$ and $Q_{m}$ liters of molasses of concentration $C_{m}(\mathrm{~g}$ sugar/l), producing the stabilized molasses solution. Solid $\mathrm{Na}_{2} \mathrm{SO}_{4}$ and water are added to the Sodium Sulfate Solution Tank to produce said $\mathrm{Na}_{2} \mathrm{SO}_{4}$ solution. The mixer operates intermittently: a mass $W$ of ground leaves $(\mathrm{kg}$, dry base) and $Q_{g}$ (liters) of stabilized molasses solution are loaded into it and taken out after a mixing time, operation that is repeated $n_{B}$ times per day. The humidity and concentrations of $\mathrm{Na}_{2} \mathrm{SO}_{4}$ and sugar in the final fodder are, respectively $X_{F, H 2 O}$ (g water/kg dry leaf), $X_{F, N a 2 S O 4}\left(\mathrm{~g} \mathrm{Na}_{2} \mathrm{SO}_{4} / \mathrm{kg}\right.$ dry leaf) and $X_{F, S U G A R}$ (g sugar/kg dry leaf). The operation shows the following problems:

1. The fresh leaf humidity causes mill clogging and stoppages. So, a dryer (Figure 1) to reduce the humidity to $X_{M, H 2 O}(\mathrm{~g}$ water $/ \mathrm{kg}$ dry leaf) is under consideration.

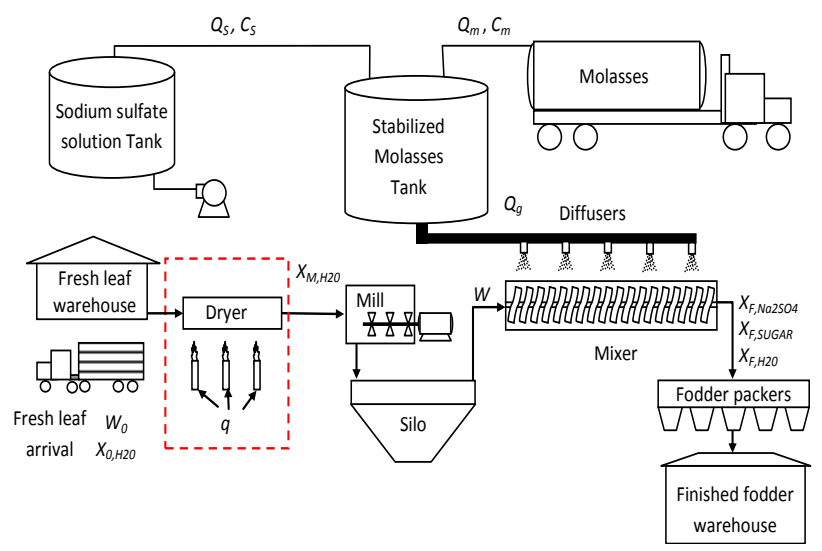

Figure 1. Cattle food plant operation

2. Solid $\mathrm{Na}_{2} \mathrm{SO}_{4}$ deposits on the Stabilized Molasses Tank outlet piping, blocking the diffusers and interrupting mixer operation. This may be fixed by adjusting the volumes and concentrations to the tank.

\section{Analysis of Objectives}

This implies identifying objectives and distinguishing those essentially important (Fundamental Objectives, FO) from those sought after for their effect on other objectives (Means Objectives, MO). For instance, the plant owner views "Maximize Profits" as a FO and "Maximize Quality" as a MO, the latter being important for its impact on sales. Objectives are structured into a Means-Ends Objectives Network (MEON) (Figure 2).

Objectives directly to the right, and connected to another through plain lines, define the latter (for instance "Maximize Profits" is measured by the metrics of "Maximize Sales" and "Minimize Costs"). An arrow from a MO to another objective means that the former benefits the latter. Alternatives are placed to the right of the MEON (In Figure 2 "Install leaf drier" is shown in red and "adjust stabilized molasses tank operation" in purple), with arrows directed to the impacted objectives. The model comprehends the path from alternatives to the head objective.

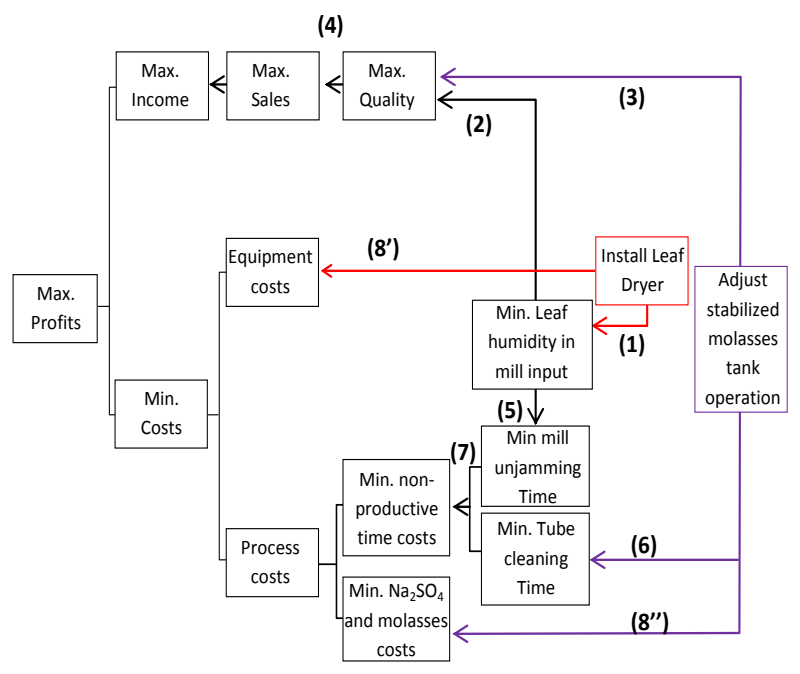

Figure 2. Means-Ends Objectives Network and alternatives ("Min."=Minimize, "Max."=Maximize)

\section{Model Construction}

The operationalization of Figure 2 connections follows. Variables are in italics (i.e. $X$ ) and probability distributions in bracketed bold fonts (i.e. $\{\boldsymbol{X}\}$ ).

Connection (1): "Install Leaf Dryer" means whether or not to install a $q(\mathrm{kcal} / \mathrm{h})$ heat load dryer. "Min. Leaf Humidity in mill input" is measured by the leaf humidity to the mill $\left(X_{M, H 20}\right)$. From the probability distributions of $W_{0}$ and $X_{0, H 20}$, mass and energy balances produce the distribution of $X_{M, H 20}$ given $q,\left\{\boldsymbol{X}_{M, H 20} \mid q\right\}$.

Connections (2) and (3): The metric of the objective originating connection 2 is $\left\{\boldsymbol{X}_{M, H z O} \mid q\right\}$. Connection 3 projects from "Adjust stabilized molasses tank operation" which implies setting the liquid volumes added to it $\left(Q_{S}\right.$ and $\left.Q_{m}\right)$, their concentrations $\left(C_{S}\right.$ and $\left.C_{m}\right)$ and the volume of stabilized molasses per mixing batch $\left(Q_{g}\right)$. As the liquid added to the tank must match the drawn amount and the molasses concentration is fixed, $C_{S}, Q_{S}$ and $Q_{g}$ are chosen as decision variables.

Quality, being not directly measurable, is clarified by constructing the "Maximize Quality" MEON (Figure 3). As connection (a) in Figure 3 shows, a quality score, (utility $U_{Q}$ ) from zero (worst) to one (best), is calculated from appearance $\left(U_{A}\right)$, nutritional value $\left(U_{N V}\right)$ and shelf life $\left(U_{S L}\right)$ utilities, as, in the owner's opinion, clients care about these fodder characteristics (Equation 1). 


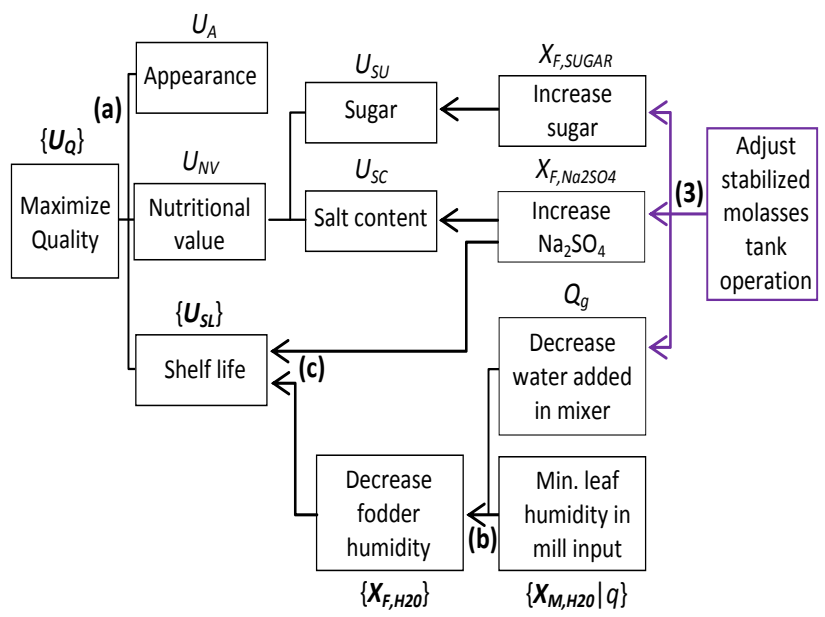

Figure 3. MEON for "Maximize Quality"

$U_{A}$ is derived from color $\left(U_{C}\right)$ and homogeneity $\left(U_{H}\right)$ utilities (Equation 2) with levels shown in Table 1.

$$
\begin{aligned}
& U_{Q}=k_{l, Q} \times U_{A}+k_{2, Q} \times U_{N V}+k_{3, Q} \times U_{S L} \\
& U_{A}=k_{l, A} \times U_{C}+k_{2, A} \times U_{H}
\end{aligned}
$$

\begin{tabular}{|c|c|c|c|c|c|}
\hline Level & Description & $U_{C}$ & Level & Description & $U_{H}$ \\
\hline Light & $\begin{array}{l}\text { Yellow or } \\
\text { straw }\end{array}$ & 1 & Low & $\begin{array}{l}\text { More than } \\
70 \% \text { of the } \\
\text { total } \\
\text { volume in } \\
\text { clumps }\end{array}$ & 0 \\
\hline Medium & $\begin{array}{l}\text { From dark } \\
\text { straw to } \\
\text { light brown }\end{array}$ & 0.6 & Medium & $\begin{array}{l}\text { Between } \\
30 \% \text { and } \\
70 \% \text { of the } \\
\text { total } \\
\text { volume in } \\
\text { clumps }\end{array}$ & 0.6 \\
\hline Dark & $\begin{array}{l}\text { Between } \\
\text { dark brown } \\
\text { and black }\end{array}$ & 0 & High & $\begin{array}{l}\text { Less than } \\
30 \% \text { of the } \\
\text { total } \\
\text { volume in } \\
\text { clumps }\end{array}$ & 1 \\
\hline
\end{tabular}

Table 1. Fodder color and homogeneity utilities

Equations (1) and (2) are instances of the additive utility function (Keeney, 1992). Their weights $\left(k_{i}\right.$ 's) and those of Equation (3) are elicited from the decision maker through a valid method (i.e. weight swinging), as are the $U$ values in Tables 1 and 2 (i.e. using the probability equivalence method) (Howard and Abbas, 2016). These values are unavoidably subjective, for they reflect the decision maker's preferences. Several tests, based on probing indifference conditions, can be used to verify their correspondence to the stakeholder's value system (Clemen, 1996).

Nutritional value utility $\left(U_{N V}\right)$ depends on the fodder sugar and $\mathrm{Na}_{2} \mathrm{SO}_{4}$ content (Equation 3). $X_{F, S U G A R}$ and $X_{F, \mathrm{Na} 2 \mathrm{SO} 4}$ were converted linearly into utilities, respectively $U_{S U}$ and $U_{S C}$, ranging from 0 at no substance to 1 at a maximum content $\left(X_{F, S U G A R}^{+}, X^{+}{ }_{F, N a 2 S O 4}\right)$ beyond which more substance doesn't enhance preference.

$$
U_{N V}=k_{l, N V} \times U_{S U}+k_{2, N V} \times U_{S C}
$$

In the context of this problem, shelf life is defined as "time (months), for stored fodder to show a color as in frame (d) of Figure 4". Table 2 shows the defined shelf life degrees and utilities $\left(U_{S L}\right)$.

Table 2. Shell life degrees definition

\begin{tabular}{lll}
\hline Shelf life degree $\left(\boldsymbol{S}_{\boldsymbol{L}}\right)$ & Description & $\boldsymbol{U}_{S L}$ \\
\hline Low & Less than 3 months & 0 \\
Medium & Between 3 and 6 months & 0.6 \\
High & More than 6 months & 1 \\
\hline
\end{tabular}

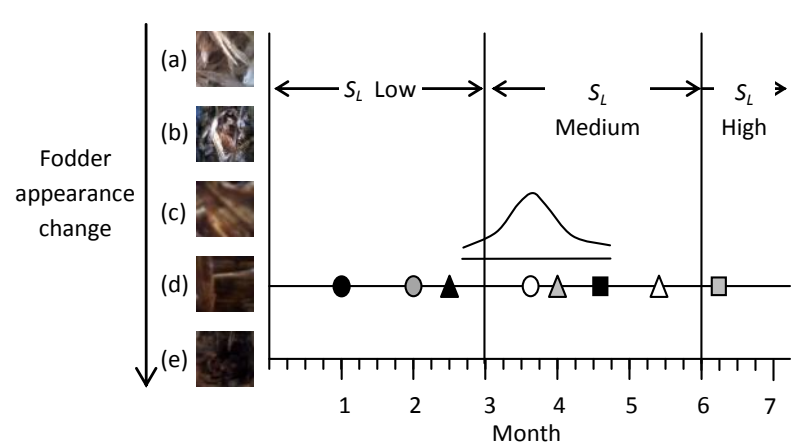

Figure 4. Graphical aid for eliciting shelf life probability distributions

The metrics of "Increase Sugar" and "Increase $\mathrm{Na}_{2} \mathrm{SO}_{4}$ ", respectively $X_{F, S U G A R}$ and $X_{F, N a 2 S O 4}$, are calculated by substance balances from $Q_{m}, C_{S}, Q_{g}$ and the mixing batch size $(W)$ (connections 3, Figure 3). $Q_{g}$ measures the "Decrease water added in mixer" objective, while a water balance around the mixer and the probability distribution of the humidity to the mill $\left\{\boldsymbol{X}_{\mathbf{M}, \mathbf{H} 20} \mid q\right\}$ provides the fodder humidity probability distribution $\left\{\boldsymbol{X}_{\boldsymbol{F}, \boldsymbol{H 2 0}}\right\}$ (connection b, Figure 3).

The shelf life depends on $X_{F, N a 2 S O 4}$ and $X_{F, H 2 O}$ (connection c, Figure 3) but no records exist to derive an histogram. The available knowledge is owner's expertise, with was encoded by probabilities elicited as follows:

a) Discrete variables $S_{C F}$ (Sulfate Concentration), with levels of "Low", "Medium" or "High" depending on $X_{F, \mathrm{Na2SO}}$, and $H_{F}$ (Fodder Humidity), taking said levels depending on $X_{F, H 2 O}$, were defined. Threshold values of $X_{F, \mathrm{Na2SO} 4}$ and $X_{F, H 20}$ for each denomination of, respectively, $S_{C F}$ and $H_{F}$, were provided by the owner.

b) Each combination of $S_{C F}$ and $H_{F}$ levels was assigned a marker, which the owner was required to place on a timeline at the time in which he thinks stored fodder would look like frame (d) of Figure 4. The shelf life is assumed to be normally distributed with mean at the marker position and a two weeks standard deviation (sketched in Figure 4 for $S_{C F}=H_{F}=$ "Low"). Once all markers are positioned, the timeline is split into shelf life degrees (defined in Table 2) and the area of the distribution falling in each zone provides the shelf life degrees $\left(S_{L}\right)$ probabilities for the relevant $\mathrm{Na}_{2} \mathrm{SO}_{4}$ content and humidity (Table 3 ). With the $U_{S L}$ values of the shelf life degrees (Table 2), a shelf life utility probability distribution $\left\{\boldsymbol{U}_{S L}\right\}$ conditional on $S_{C F}$ and $H_{F}$ is derived. In summary, the "Maximize Quality" model in Figure 3 converts decisions $Q_{m}, C_{\mathrm{S}}$ and $Q_{g}$ and the distribution of the leaf water content to the mill $\left\{\boldsymbol{X}_{M, H 20} \mid q\right\}$ into a quality utility distribution $\left\{\boldsymbol{U}_{Q}\right\}$. 
Table 3. Shelf Life degrees $\left(S_{L}\right)$ probabilities conditioned on fodder $\mathrm{Na}_{2} \mathrm{SO}_{4}$ and water content

\begin{tabular}{|c|c|c|c|c|c|c|c|c|c|c|}
\hline \multirow{2}{*}{\multicolumn{2}{|c|}{$\begin{array}{l}S_{C F} \\
H_{F}\end{array}$}} & \multicolumn{3}{|c|}{$\mathbf{L}$} & \multicolumn{3}{|c|}{ M } & \multicolumn{3}{|c|}{ H } \\
\hline & & $\mathbf{L}$ & M & $\mathbf{H}$ & $\mathbf{L}$ & M & H & $\mathbf{L}$ & $\mathbf{M}$ & $\mathbf{H}$ \\
\hline Marke & & 0 & 0 & 8 & $\Delta$ & $\Delta$ & $\Lambda$ & $\square$ & $\square$ & \\
\hline \multirow{3}{*}{$S_{L}$} & $\mathrm{~L}$ & 0.15 & 0.95 & 1 & 0 & 0.1 & 0.75 & 0 & 0 & 0 \\
\hline & M & 0.85 & 0.05 & 0 & 0.8 & 0.9 & 0.25 & 0 & 0.4 & 1 \\
\hline & $\mathrm{H}$ & 0 & 0 & 0 & 0.2 & 0 & 0 & 1 & 0.6 & 0 \\
\hline
\end{tabular}

L=Low; M=Medium; H=High

Connection (4): The relation between monthly sales $(V)$ and $U_{Q}$ is assumed quadratic, regressed from the current quality utility $\left(U^{0} \mathrm{Q}\right)$ and sales $\left(V^{0}\right)$ operation point; point $\left(1, \alpha V^{0}\right)$ where $\alpha V^{0}$ are the monthly sales were $U_{Q}$ raised to 1 , and point $(0$, $\beta V^{0}$ ), where $\beta V^{0}$ are the sales if $U_{Q}$ equals 0 . The plant sales staff provided estimates of $\alpha$ and $\beta$.

Connection (5): The connection from leaf humidity $\left(X_{M, H 20}\right)$ to the daily hours lost to mill jams $\left(N_{P M}\right)$, relies on operators' experience. First a "Leaf Humidity to the Mill" variable $\left(H_{M}\right)$ is defined, being "Low", "Medium" or "High" depending on $X_{M, H 20}$. Then, the probability distribution of the number of hourly mill stoppages $\left(n_{M S}\right)$ conditional on $H_{M}$ was elicited (Table 4).

The mill downtime, $t_{\mathrm{C}}(\mathrm{h})$, varies uniformly between low $\left(t_{C}{ }^{-}\right)$and high $\left(t_{C}{ }^{+}\right)$values, contingent on $H_{M}$ (Table 5). In absence of data, the uniform, triangular and beta distributions are often used to model inputs (Banks et al., 2010). While the uniform distribution is regarded as a poor choice, as process time distributions tend to be somewhat centralized, it can be used as an initial approach to the phenomena (Harrell et al., 2012). Additionally, a uniform distribution can sometimes represent what is really known of a variable, and imposing further restrictions on the form of its distribution amounts to assuming less uncertainty than that actually present (Hubbard, 2014).

Table 4. Probabilities of $n_{M S}$ conditioned on $H_{M}$

\begin{tabular}{llll}
\hline & $\boldsymbol{H}_{\boldsymbol{M}}$ & & \\
$\boldsymbol{n}_{\boldsymbol{M S}}$ & Low & Medium & High \\
\hline 0 & 0.8 & 0.2 & 0 \\
1 & 0.2 & 0.6 & 0.4 \\
2 & 0 & 0.2 & 0.6 \\
\hline
\end{tabular}

Table 5. Maximum and minimum values of $t_{C}$ for different $H_{M}$ levels (hours)

\begin{tabular}{llll}
\hline & $\boldsymbol{H}_{\boldsymbol{M}}$ & & \\
& Low & Medium & High \\
\hline$t_{C^{-}}$ & $5 / 60$ & $10 / 60$ & $12 / 60$ \\
$t_{C^{+}}$ & $7 / 60$ & $15 / 60$ & $17 / 60$ \\
\hline
\end{tabular}

When analysts need to resort to probabilities or probability distribution parameters elicited directly from experts, as those in Tables 4 and 5, care should be taken that the expert is properly calibrated and the information is obtained through a valid procedure, like the probability wheel or the probability equivalent methods (Morgan and Henrion, 1990). Additionally, tests of consistency and coherence of the set of elicited probabilities should be performed (Lindley, 2006).

To fulfil a processing requirement of $W_{0} \mathrm{~kg}$ of leaves in an $8 \mathrm{~h}$ day, the mill should process a mass $(w)$ of $W_{0} / 8$ per hour. If the milling hourly rate is $\omega$, the grinding time $\left(T_{w}\right)$ for $w \mathrm{~kg}$ is $(w / \omega)$ plus mill unjamming time, which depends on the leaf humidity distribution $\left\{\boldsymbol{X}_{M, H 20}\right\}$ through Tables 4 and 5. The sum of the $T_{w}$ 's for all eight sized $w$ amounts, produces the needed daily milling time $\left(T_{M I L L}\right)$, being $N_{P M}=$ $\operatorname{Max}\left\{T_{M I L}-8,0\right\} \mathrm{h}$.
Connection (6): "Minimize tube cleaning time" is measured by the daily wasted hours due to $\mathrm{Na}_{2} \mathrm{SO}_{4}$ blockages $\left(N_{P T}\right)$. Sulfate obstruction is given by its solubility $C^{*}\left(T_{S T}\right)$ (depending on the stabilized molasses tank temperature, $T_{S T}$ ), the volume $\left(Q_{S}\right)$ of sulfate solution of concentration $\left(C_{S}\right)$ added to the tank, and the amount $(m)$ that suffices to block the outlet piping. The number of blockages occurring daily $\left(n_{T B}\right)$ is estimated as $Q_{S} \times\left(C_{S}-C^{*}\left(T_{S T}\right)\right) / m$ if $C_{S}>C^{*}\left(T_{S T}\right)$ and zero otherwise. If clearing the solid $\mathrm{Na}_{2} \mathrm{SO}_{4}$ from the tubes takes $d_{C}$ hours, the hours lost per day are $N_{P T}=d_{C} \times n_{T B}$. The tank temperature distribution $\left\{\boldsymbol{T}_{\boldsymbol{S T}}\right\}$ is taken as triangular with minimum, maximum and most likely values of, respectively $T_{M I N}, T_{M A X}$ and $T_{M L}$, while $\{\boldsymbol{m}\}$ is uniformly distributed between $m_{M I N}$ and $m_{M A X}$. From $Q_{S}$ and $C_{S}$ and said distributions, $\left\{N_{P T}\right\}$ can be derived.

Connections (7,8): "Minimize Process Costs" is measured by the annual savings for reducing mill jams $\left(\Delta D_{0}\right)$ and the yearly cost of $\mathrm{Na}_{2} \mathrm{SO}_{4}$ tube blockages (Cost $t_{T U}$ ). For 260 working days/year, a staff wage of $a_{S}(\$ / \mathrm{h})$ and a current number of daily hours lost at the mill of $N^{0}{ }_{P M}$, $\Delta D_{0}=260 \times a_{S} \times\left(N_{P M}^{0}-\mathrm{E}\left[N_{P M}\right]\right)$ and $\operatorname{Cost}_{T V}=260 \times a_{S} \times \mathrm{E}\left[N_{P T}\right]$ $\left(\mathrm{E}\left[N_{P M}\right]\right.$ and $\mathrm{E}\left[N_{P T}\right]$ are, respectively, the expected values of $N_{P M}$ and $N_{P T}$ ). The annualized dryer cost $\operatorname{Cost}_{D R}(q)$ depends on its heat load $(q)$, while the substance costs (Costsubs) on the amount of $\mathrm{Na}_{2} \mathrm{SO}_{4}$ and molasses spent. If $\mathrm{E}[\mathrm{V}]$ is the expected value of the monthly sales, the overall objective function is

$Z=12 \times E[V]+\Delta D_{\sigma}-\operatorname{Cost}_{T U}-\operatorname{Cost}_{D R}(q)-\operatorname{Cost}_{S U B S}$

Finally, it is necessary to comment on how the model was validated, that is, how it was checked that it was a fair representation of reality. Strictly speaking, validating a model means contrasting its predictions with observations. However, in the present context, such a validation could only be done to the connections relying on material and energy balances (connections 1 and 3). For most other model connections, which rely on subjective probabilities, no data are available for a validation exercise (that's why these connections were modeled using expert's experience, in the first place). This doesn't mean, however, that no quality assessment could be done of these connections: the elicited subjective probability distributions were checked for coherency and consistency (i.e. that they comply with probability rules) and the connection results "face value" was confirmed by the experts, meaning that they were deemed reasonable. Similarly, for the connections modelling preferences (i.e. equation 3) there are not experimental values to contrast their output with, however, their adequacy was tested by presenting the stakeholder with several choices, and checking that the preferred choice matched the predicted ones.

\section{Results and Discussion}

Table 6 shows the numerical values used in generating the results. As the fodder appearance is unaffected by the alternatives, $k_{1, Q}$ was set to zero and so the parameters of Equation (2) were not required.

The mass of fresh leaves arriving daily $\left(W_{0}\right)$ is uniformly distributed between 600 and 1 '000 (kg leaf-dry base/day), with an humidity $X_{0, H 20}$ distributed normally with mean 174,1 and standard deviation of 20 (g water $/ \mathrm{kg}$ dry leaf). Three possible dryers are considered, with heat loads respectively of 3'000 $\mathrm{kcal} / \mathrm{h}, 5^{\prime} 000$ and $7^{\prime} 000 \mathrm{kcal} / \mathrm{h}$ and annualized total cost, respectively, of $\$ 8^{\prime} 600, \$ 30^{\prime} 000$ and $\$ 70^{\prime} 000$. 
For solving the model, it is necessary to find values of the decision variables: dryer heat load, $C_{S}, Q_{m}$ and $Q_{g}$ maximizing equation (4). The first is a discrete variable, with possibilities of cero, 3'000 kcal/h, 5'000 and $7^{\prime} 000 \mathrm{kcal} / \mathrm{h}$, while the other are continuous. For each dryer heat load, the variables $C_{S}, Q_{m}$ and $Q_{g}$ where changed through a random-walk algorithm (Rao, 1996). First, said three variables were grouped in a vector $\mathbf{X}$ and, starting at an initial value $\mathbf{X}^{0}$, several random directions $\Delta \mathbf{X}$ are explored, and the one producing the a greatest value of equation (4) at $\mathbf{X}^{0}+\Delta \mathbf{X}$ is selected. Then $\mathbf{X}$ moves from $\mathbf{X}^{0}$ in the direction $\Delta \mathbf{X}$, until the objective function no longer increases. At the arrived point, a new movement direction is sought. This is repeated until no improvement direction can be found.

From the search results included in Table 7, the best alternative is a 5'000 kcal/h dryer and to operate the stabilized molasses tank with $C_{S}=254 \mathrm{~g} / \mathrm{l}, Q_{m}=11$ liters and $Q_{g}=13$ liters.

Table 6. Parameter values

\begin{tabular}{|c|c|c|c|}
\hline Symbol & Description & Units & Value \\
\hline$W$ & $\begin{array}{l}\text { Weight of a batch to the } \\
\text { mixer }\end{array}$ & $\begin{array}{l}\text { kg leaf (dry } \\
\text { base) }\end{array}$ & 100 \\
\hline$n_{B}$ & $\begin{array}{l}\text { Batches fed daily to the } \\
\text { mixer }\end{array}$ & & 10 \\
\hline$C_{m}$ & $\begin{array}{l}\text { Molasses sugar } \\
\text { concentration }\end{array}$ & g sugar $/ 1$ & 500 \\
\hline$k_{l, Q}$ & $\begin{array}{l}\text { Appearance weight in } \\
\text { quality }\end{array}$ & & 0 \\
\hline$k_{2, Q}$ & $\begin{array}{l}\text { Nutritional value weight in } \\
\text { quality }\end{array}$ & & 0.3 \\
\hline$k_{3, Q}$ & Shelf life weight in quality & & 0.7 \\
\hline $\mathrm{X}^{+} \mathrm{F}, \mathrm{Na} 2 \mathrm{SO} 4$ & $\begin{array}{l}\text { Preferred maximum value of } \\
X_{F, \mathrm{Na} 2 \mathrm{SO} 4} \text { for its nutritional } \\
\text { value }\end{array}$ & $\begin{array}{l}\mathrm{g} \mathrm{Na}_{2} \mathrm{SO}_{4} / \\
\text { kg dry leaf }\end{array}$ & 80 \\
\hline$X^{+}{ }_{F, S U G A R}$ & $\begin{array}{l}\text { Preferred maximum value of } \\
X_{F, S U G A R} \text { for its nutritional } \\
\text { value }\end{array}$ & $\begin{array}{l}\text { g sugar / kg } \\
\text { dry leaf }\end{array}$ & 100 \\
\hline$k_{l, N V}$ & $\begin{array}{l}\text { Importance of sugar in the } \\
\text { forage nutritional value }\end{array}$ & & 0.7 \\
\hline$k_{2, N V}$ & $\begin{array}{l}\text { Importance of } \mathrm{Na}_{2} \mathrm{SO}_{4} \text { in the } \\
\text { forage nutritional value }\end{array}$ & & 0.3 \\
\hline$b_{\mathrm{Na} 2 \mathrm{SO}} 4$ & $\begin{array}{l}\text { Maximum value of } X_{F, \mathrm{Na} 2 \mathrm{SO}} \\
\text { for } S_{C F}=\mathrm{Low}\end{array}$ & $\begin{array}{l}\mathrm{g} \mathrm{Na}_{2} \mathrm{SO}_{4} / \\
\text { kg dry leaf }\end{array}$ & 30 \\
\hline$a_{\mathrm{Na} 2 \mathrm{SO} 4}$ & $\begin{array}{l}\text { Minimum value of } X_{F, N a 2 S O 4} \\
\text { for } S_{C F}=\text { High }\end{array}$ & $\begin{array}{l}\mathrm{g} \mathrm{Na}_{2} \mathrm{SO}_{4} / \\
\text { kg dry leaf }\end{array}$ & 80 \\
\hline$b_{F, H 2 O}$ & $\begin{array}{l}\text { Maximum value of } X_{F, H 2 O} \text { for } \\
H_{F}=\text { Low }\end{array}$ & $\begin{array}{l}\text { g water/kg } \\
\text { dry leaf }\end{array}$ & 150 \\
\hline$a_{F, H 2 O}$ & $\begin{array}{l}\text { Minimum value of } X_{F, H 2 O} \text { for } \\
H_{F}=\text { High }\end{array}$ & $\begin{array}{l}\text { g water / kg } \\
\text { dry leaf }\end{array}$ & 300 \\
\hline$V^{0}$ & Current monthly sales & \$/ month & 100000 \\
\hline$U_{S U}^{0}$ & Current $U_{S U}$ value & & 0.5 \\
\hline$U_{S C}^{0}$ & Current $U_{S C}$ value & & 0.5 \\
\hline$U_{N V}^{0}$ & Current $U_{N V}$ value & & 0.5 \\
\hline$U_{S L}^{0}$ & Current $U_{S L}$ value & & 0.15 \\
\hline$U_{Q}^{0}$ & Current $U_{Q}$ value & & 0.255 \\
\hline$\alpha$ & Sales increase factor if $U_{Q}=1$ & $>1$ & 1.2 \\
\hline$\beta$ & $\begin{array}{l}\text { Sales decrease factor if } U_{Q}= \\
0\end{array}$ & $<1$ & 0.2 \\
\hline$b_{M, H 2 O}$ & $\begin{array}{l}\text { Maximum value of } X_{M, H 2 O} \\
\text { for } H_{M}=\text { Low }\end{array}$ & $\begin{array}{l}\text { g water } / \mathrm{kg} \\
\text { dry leaf }\end{array}$ & 40 \\
\hline$a_{M, H 2 O}$ & $\begin{array}{l}\text { Minimum value of } X_{M, H 20} \text { for } \\
H_{M}=\text { High }\end{array}$ & $\begin{array}{l}\text { g water } / \mathrm{kg} \\
\text { dry leaf }\end{array}$ & 100 \\
\hline$\omega$ & Mill processing rate & $\begin{array}{l}\text { kg leaf (dry } \\
\text { base)/h }\end{array}$ & 120 \\
\hline
\end{tabular}

\begin{tabular}{|c|c|c|c|}
\hline Symbol & Description & Units & Value \\
\hline$N^{0} P M$ & $\begin{array}{l}\text { Current number of hours lost } \\
\text { to mill jams }\end{array}$ & $\mathrm{h} / \mathrm{day}$ & 3 \\
\hline$T_{M A X}$ & $\begin{array}{l}\text { Maximum temperature of } \\
\text { the stabilized molasses } \\
\text { solution }\end{array}$ & ${ }^{0} \mathrm{C}$ & 18 \\
\hline$T_{M I N}$ & $\begin{array}{l}\text { Minimum temperature of the } \\
\text { stabilized molasses solution }\end{array}$ & ${ }^{0} \mathrm{C}$ & 10 \\
\hline$T_{M L}$ & $\begin{array}{l}\text { Most likely temperature of } \\
\text { the stabilized molasses } \\
\text { solution }\end{array}$ & ${ }^{0} \mathrm{C}$ & 15 \\
\hline$C^{*}\left(T_{M A X}\right)$ & $\mathrm{Na}_{2} \mathrm{SO}_{4}$ solubility at $T_{M A X}$ & $\mathrm{~g} / \mathrm{l}$ & 174 \\
\hline $\mathrm{C}^{*}\left(T_{\mathrm{MIN}}\right)$ & $\mathrm{Na}_{2} \mathrm{SO}_{4}$ solubility at $T_{M I N}$ & $\mathrm{~g} / \mathrm{l}$ & 90 \\
\hline $\mathrm{C} *\left(T_{\mathrm{ML}}\right)$ & $\mathrm{Na}_{2} \mathrm{SO}_{4}$ solubility at $T_{M L}$ & $\mathrm{~g} / \mathrm{l}$ & 143 \\
\hline$m_{M A X}$ & $\begin{array}{l}\text { Maximum value of the } \\
\text { distribution of } m\end{array}$ & $\mathrm{~g}$ & 5000 \\
\hline$m_{M I N}$ & $\begin{array}{l}\text { Minimum value of the } \\
\text { distribution of } m\end{array}$ & $\mathrm{~g}$ & 4000 \\
\hline$n^{0} T B$ & $\begin{array}{l}\text { Current number of } \mathrm{Na}_{2} \mathrm{SO}_{4} \\
\text { tube blockages per day }\end{array}$ & & 3 \\
\hline$d_{C}$ & $\begin{array}{l}\text { Time required to clear a } \\
\mathrm{Na}_{2} \mathrm{SO}_{4} \text { tube blockage }\end{array}$ & hours & 0.25 \\
\hline \multirow[t]{3}{*}{ as } & Hourly staff wage & $\$ / h$ & 5 \\
\hline & Cost of $\mathrm{Na}_{2} \mathrm{SO}_{4}$ & $\$ / \mathrm{kg}$ & 5 \\
\hline & Cost of molasses & $\$ / 1$ & 5 \\
\hline
\end{tabular}

The expected annual profits may also be increased by almost $\$ 180 ' 000$ by adjusting the operation of the stabilized molasses tank (Table 7, “Optimized" row). Said change causes the blockages costs to rise from their original values (from $\$ 977$ to $\$ 1 ' 176$ ), but this is offset by enhanced sales and substance cost reduction.

Table 7a. Optimization Results

\begin{tabular}{|c|c|c|c|c|c|}
\hline & $\begin{array}{c}C_{S} \\
(\mathrm{~g} / \mathrm{l})\end{array}$ & $Q_{m}(\mathbf{l})$ & $Q_{g}(\mathbf{l})$ & $\begin{array}{c}\text { Sales } \\
\text { (\$/ year) }\end{array}$ & $\begin{array}{c}\text { Dryer } \\
\text { Cost } \\
\text { (\$/ year) }\end{array}$ \\
\hline Original & 200 & 100 & 30 & $\$ 1200000$ & - \\
\hline Optimized & 278 & 16 & 13 & $\$ 1259476$ & - \\
\hline $3000 \mathrm{kcal} / \mathrm{hr}$ & 282 & 47 & 15 & $\$ 1418469$ & $\$ 8600$ \\
\hline $5000 \mathrm{kcal} / \mathrm{hr}$ & 254 & 11 & 13 & $\$ 1419186$ & $\$ 30000$ \\
\hline $7000 \mathrm{kcal} / \mathrm{hr}$ & 285 & 3 & 11 & $\$ 1446777$ & $\$ 70000$ \\
\hline
\end{tabular}

Table 7b. Optimization Results (cont.)

\begin{tabular}{lccccc}
\hline & $\begin{array}{c}\text { Savings by } \\
\text { mill jam } \\
\text { reduction } \\
\text { (\$/year) }\end{array}$ & $\begin{array}{c}\text { Tube Na2SO4 } \\
\text { blockage cost } \\
\text { (\$year) }\end{array}$ & $\begin{array}{c}\text { Substance } \\
\text { Cost } \\
\text { (\$/ year) }\end{array}$ & $\begin{array}{c}\text { Objective } \\
\text { function } \\
\text { (\$/year) }\end{array}$ \\
\hline Original & - & $\$ 977$ & $\$ 182000$ & $\$ 1017022$ \\
Optimized & - & $\$ 1176$ & $\$ 61125$ & $\$ 1197174$ \\
$3000 \mathrm{kcal} / \mathrm{hr}$ & $\$ 120$ & $\$ 1174$ & $\$ 100376$ & $\$ 1308630$ \\
$5000 \mathrm{kcal} / \mathrm{hr}$ & $\$ 6208$ & $\$ 1056$ & $\$ 53574$ & $\$ 1335176$ \\
$7000 \mathrm{kcal} / \mathrm{hr}$ & $\$ 12010$ & $\$ 1173$ & $\$ 43543$ & $\$ 1333262$ \\
\hline
\end{tabular}

\section{Conclusions}

The management of industries and manufactures is affected by uncertainty, whose reduction may be unaffordable for small or medium-sized companies. Thus, the decision modelling for such companies should strive to make the most of the information at hand. However, this emphasis carries the responsibility of keeping modeling assumptions transparent, so they can be critically assessed. This work aims to show, by 
detailing the analysis of the issues of a fodder plant, how a Value Focused Thinking approach leads to a modelling process fulfilling said requirements. Model construction proceeds over a backbone of connected objectives, and is carried out by systematically operationalizing the connections.

No claim is made that the specific manner in which the connections between objectives were operationalized in the presented worked example is unique or optimal. However, the methodical, connection-based modelling construction procedure facilitates identifying those assumptions more open to debate, making it easy to substitute them in the relevant connections if additional information becomes available. It is expected that the modelling approach shown here can be useful in situations where decisions must be taken with scarce or limited information.

\section{References}

1. Agrell, P.J., Stam, A., and Fischer, G.W., Interactive multiobjective agro-ecological land use planning: The Bungoma region in Kenya, European Journal of Operational Research, 158(1), 2004, pp. 194-217, DOI: 10.1016/S0377-2217(03)00355-2.

2. Ahmed, M. M., Preckel, P.V., Baker, T.G., and LopezPereira, M., Modeling the impact of technological change on nutrition and marketed surplus, Agricultural Economics, 25(1), 2001, pp. 103-118, DOI: 10.1016/S01695150(00)00082-7

3. Banks, J., Carson II, J.S., Nelson, B.L., and Nicol, D.M., Discrete-event system simulation, Prentice Hall, USA, 2010.

4. Barton, D.N., Benjamin, T., Cerdán, C.R., DeClerck, F., Madsen, A.L., Rusch, G.M., Salazar, A.G., Sanchez, D., and Villanueva, C., Assessing ecosystem services from multifunctional trees in pastures using Bayesian belief networks, Ecosystem Services, 18, 2016, pp. 165-174, DOI: 10.1016/j.ecoser.2016.03.002.

5. Clemen, R.T., Making Hard Decisions: An introduction to decision analysis, Duxbury Press, USA, 1996.

6. Dorshorst, N.C., Collins, M.T., and Lombard, J.E., Decision analysis model for paratuberculosis control in commercial dairy herds, Preventive Veterinary Medicine, 75(1,2), 2006, pp. 92-122, DOI: 10.1016/j.prevetmed. 2006.02.002.

7. Harrell, C., Ghosh, B.K., Bowden, R.O., Simulation using promodel, McGraw Hill, USA, 2012.

8. Hosseinzade, Z., Pagsuyoin, S.A., Ponnambalam, K., and Monem, M.J., Decision-making in irrigation networks: Selecting appropriate canal structures using multiattribute decision analysis, Science of the Total Environment, 601, 2017, pp. 177-185, DOI: 10.1016/j.scitotenv. 2017.05.189.

9. Howard, R.A., Decision Analysis: Applied Decision Theory, Proceedings of the Fourth International Conference on Operational Research, 1996, pp. 57-71.

10. Howard, R.A., and Abbas, A.E., Foundations of Decision Analysis, Pearson, USA, 2016.

11. Hubbard, D.W., How to measure anything: finding the value of intangibles in business, John Wiley and sons, USA, 2014.
12. Jha, M.K., Chowdary, V.M., Kulkarni, Y., and Mal, B.C., Rainwater harvesting planning using geospatial techniques and multicriteria decision analysis, Resources, Conservation and Recycling, 83, 2014, pp. 96-111, DOI: doi.org/10.1016/j.resconrec.2013.12.003.

13. Keeney, R.L., Value-Focused Thinking. A path to creative Decision Making, Harvard University Press, USA, 1992.

14. Kocjančič, T., Debeljak, M., Žgajnar, J., and Juvančič, L., Incorporation of emergy into multiple-criteria decision analysis for sustainable and resilient structure of dairy farms in Slovenia, Agricultural Systems, 164, 2018, pp. 71-83.

15. Lien, G., Assisting whole-farm decision-making through stochastic budgeting, Agricultural Systems, 76(2), 2003, pp. 399-413, DOI: 10.1016/S0308-521X (02)00079-3

16. Lindley, D.V., Understanding Uncertainty, John Wiley and Sons, USA, 2006.

17. Monjardino, M., McBeath, T., Ouzman, J., Llewellyn, R., and Jones, B., Farmer risk-aversion limits closure of yield and profit gaps: A study of nitrogen management in the southern Australian wheat belt, Agricultural Systems, 137, 2015, pp. 108-118, DOI: 10.1016/j.agsy.2015.04. 006.

18. Morgan, M.G., and Henrion, M., Uncertainty: A guide to dealing with uncertainty in Quantitative Risk and Policy Analysis, Cambridge University Press, USA, 1990.

19. Mwambo, F. M., Fürst, C., Nyarko, B.K., Borgemeister, C., and Martius, C., Maize production and environmental costs: Resource evaluation and strategic land use planning for food security in northern Ghana by means of coupled emergy and data envelopment analysis, Land Use Policy, 95, 2020, article 104490 .

20. Nikoloski, T., Udovč, A., Pavlovič, M., and Rajkovič, U., Farm reorientation assessment model based on multicriteria decision making, Computers and Electronics in Agriculture, 140, 2017, pp. 237-243, DOI: 10.1016/ j.compag.2017.06.011.

21. Oltenacu, P.A., Ferguson, J.D., and Lednor, A.J., Economic Evaluation of Pregnancy Diagnosis in Dairy Cattle: A Decision Analysis Approach, Journal of Dairy Science, 73(10), 1990, pp. 2826-2831, DOI: 10.3168/jds. S0022-0302(90)78970-9.

22. Parsons, T.D., Smith, G., and Galligan, D.T., Economics of porcine parvovirus vaccination assessed by decision analysis, Preventive Veterinary Medicine, 4(3), 1986, pp. 199-204, DOI: 10.1016/0167-5877(86)90023-1.

23. Plà, L.M., Pomar, C., and Pomar, J., A sow herd decision support system based on an embedded Markov model, Computers and Electronics in Agriculture, 45(1-3), 2004, pp. 51-69, DOI: 10.1016/j.compag.2004.06.005.

24. Põldaru, R., and Roots, J., Using a nonlinear stochastic model to schedule silage maize harvesting on Estonian farms, Computers and Electronics in Agriculture, 107, 2014, pp. 89-96, DOI: 10.1016/j.compag.2014.06.007.

25. Prato, T., and Herath, G., Multiple-criteria decision analysis for integrated catchment management, Ecological Economics, 63(2-3), 2007, pp. 627-632, DOI: 10.1016/ j.ecolecon.2007.01.003. 
26. Punantapong, B., Evaluation Models for Decision Support in the Context of Organic Farming System, Agriculture and Agricultural Science Procedia, 11, 2016, pp. 105-111, DOI: 10.1016/j.aaspro.2016.12.018.

27. Rao, S.S., Engineering Optimization, John Wiley and Sons, USA, 1996.

28. Rocchi, L., Paolotti, L., Rosati, A., Boggia, A., and Castellini, C., Assessing the sustainability of different poultry production systems: A multicriteria approach, Journal of Cleaner Production, 211(20), 2019, pp. 103114.

29. Romano, G., Dal Sasso, P., Trisorio, L. G., and Gentile, F., Multi-criteria decision analysis for land suitability mapping in a rural area of Southern Italy, Land Use Policy, 48, 2015, pp. 131-143, DOI: 10.1016/j.landusepol.2015.05.013.

30. Shastri, Y., Hansen, A., Rodríguez, L., and Ting, K.C., Development and application of BioFeed model for optimization of herbaceous biomass feedstock production, Biomass and Bioenergy, 35(7), 2011, pp. 2961-2974, DOI: 10.1016/j.biombioe.2011.03.035.

31. Silva, G. S., Corbellini, L. G., Linhares, D. L. C., Baker, K.L., and Holtkamp, D. J., Development and validation of a scoring system to assess the relative vulnerability of swine breeding herds to the introduction of PRRS virus, Preventive Veterinary Medicine, 160, 2018, pp. 116-122.

32. Toosi, A. S., Tousi, E. G., Ghassemi, S.A., Cheshomi, A., and Alaghmand, S., A multi-criteria decision analysis approach towards efficient rainwater harvesting, Journal of Hydrology, 582, 2020, article 124501.

33. Topping, C.J., Dalby, L., and Valdez, J.W., Landscapescale simulations as a tool in multi-criteria decision making to support agri-environment schemes, Agricultural Systems, 176, 2019, article 102671.

34. Widodo, K.H., Nagasawa, H., Morizawa, K., and Ota, M., A periodical flowering-harvesting model for delivering agricultural fresh products, European Journal of Operational Research, 170(1), 2006, pp. 24-43, DOI: 10.1016/j.ejor.2004.05.024.

35. Yin, S., Takeshige, A., Miyake, Y., and Kimura, S., Selection of suitable coastal aquaculture sites using MultiCriteria Decision Analysis in Menai Strait, UK, Ocean \& Coastal Management, 1651, 2018, pp. 268-279.

36. Zerger, A., Warren, G., Hill, P., Robertson, D., Weidemann, A., and Lawton, K., Multi-criteria assessment for linking regional conservation planning and farm-scale actions, Environmental Modelling and Software, 26(1), 2011, pp. 103-110, DOI: 10.1016/j.envsoft.2010.04.001. 